\title{
Parameter Study of In-Situ Grown Superconducting YBaCuO Thin Films Prepared by Laser Ablation
}

D.H.A.Blank, D.J.Adelerhof, J.Flokstra and H.Rogalla,

University of 'Twente, P.O.Box 217, 7500 AE, Enschede, The Netherlands.

A parameter study has been made of $\mathrm{YBaCuO}$ thin films prepared by laser ablation. The films were deposited on $\mathrm{SrTiO}_{3}$, $\mathrm{MgO}$, and $\mathrm{Si}$ with $\mathrm{ZrO}_{2}$ buffer layer at substrate temperatures between $600^{\circ} \mathrm{C}-800^{\circ} \mathrm{C}$. With optimization of different parameters like substrate temperature, pulse frequency, target-substrate distance, and oxygen pressure, zero resistivity was derived for the in-situ grown films on $\mathrm{SrTiO}_{3}$ at $89.5 \mathrm{~K}$, on $\mathrm{MgO}$ at $84.6 \mathrm{~K}$, and on $\mathrm{Si}_{(\mathrm{ZrO}}$ ) at $83.5 \mathrm{~K}$.

\section{Laser Ablation, Experimental details}

Several techniques have been used for manufacturing high Tc thin films. Especially, in-situ preparation leads to high-quality films, with c-axis orientation and high critical current densities 1 .

In this paper we describe the results of the fabrication of $\mathrm{YBa}_{2} \mathrm{Cu}_{3} \mathrm{O}_{7-\delta}$ films by means of laser ablation on substrates of $\mathrm{SrTiO}_{3}$ (100), $\mathrm{MgO}$ (100), and $\mathrm{Si}$ (111) with $\mathrm{ZrO}_{2}$.

The experiments were carried out with an excimer laser in the $\mathrm{XeCl}$ mode, including an unstable resonator providing a better focus of the laser bundle. The target, mounted on a rotatable table, is a pellet of $\mathrm{YBa}_{2} \mathrm{Cu}_{3} \mathrm{O}_{7-\delta}$ prepared with the citrate/pyrolysis method ${ }^{2}$ and has a diameter of $16 \mathrm{~mm}$. The spot size of the laser is $2 \mathrm{~mm}^{2}$. The energy density was kept at about $2 \mathrm{~J} / \mathrm{cm}^{2}$. The substrate is attached to a stainless steel plate heated by a $\mathrm{NiCr}$ wire and substrate temperatures up to about $800^{\circ} \mathrm{C}$, measured by a pyrometer, can be obtained. The distance between target and substrate is adjustable. In the experiments the substrate temperature, the pulse frequency and the target-substrate distance were used as variable parameters. The oxygen pressure during the ablation was about 0.3 mbar and after deposition the sample was cooled down to room temperature in about 1 hour at an oxygen pressure of 1 bar. These in-situ prepared films are superconducting and no anneal procedure is necessary.

\section{Results}

In order to obtain $\mathrm{YBaCuO}$ thin films with the correct stoichiometry, the substrate has to be put on the border region of the plasma. This plasma is influenced by the density of the target, the energy density of the laser beam, and the oxygen pressure in the chamber. With an energy density of $2 \mathrm{~J} / \mathrm{cm}^{2}$ and an oxygen pressure of $0.3 \mathrm{mbar}$, good results were obtained with a target to substrate distance of 25 to $35 \mathrm{~mm}$. With these adjustments the deposition rate is typically $1 \AA /$ shot.

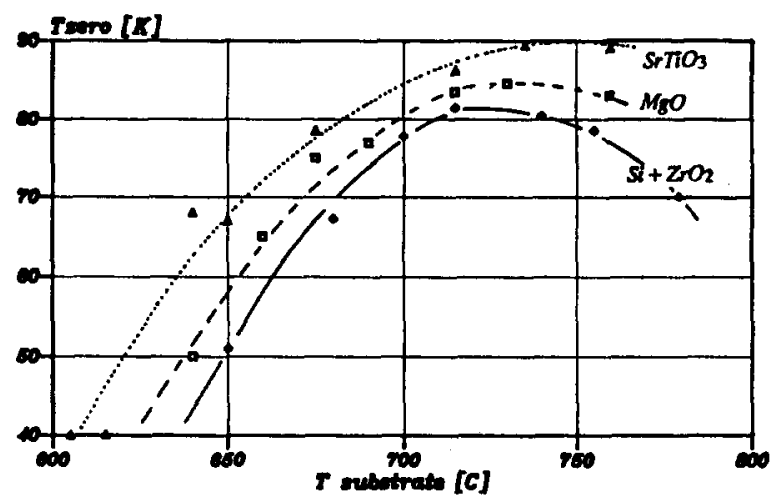

\section{FIGURE 1}

The influence of the substrate temperature on $T_{\text {zero }}$ for $\mathrm{SrTiO}_{3} \mathrm{MgO}$, and $\mathrm{Si}+\mathrm{ZrO}_{2}$.

Resistivity measurements of $\mathrm{YBaCuO}$ films on $\mathrm{SrTiO}_{3}, \mathrm{MgO}$, and $\mathrm{Si}$ with $\mathrm{ZrO}_{2}$ buffer layer show the strong influence of the substrate temperature $\mathrm{T}_{\text {subs. }}$ All 
films have an onset temperature $\mathrm{T}_{\text {onset }}$ of about $90 \mathrm{~K}$ and a zero resistivity temperature $\mathbf{T}_{\text {zero }}$ strongly dependent on the substrate material and its deposition temperature. In fig. 1 the relation between $\mathrm{T}_{\text {zero }}$ and $\mathrm{T}_{\text {subs }}$ is given for a pulse frequency of $2 \mathrm{~Hz}$ and a deposition time of $30 \mathrm{~min}$. The typical film thickness is about $300 \mathrm{~nm}$ and the films are, even in the $\mathrm{Si}-\mathrm{ZrO}_{2}$ case, c-axis oriented at sufficiently high substrate temperatures.

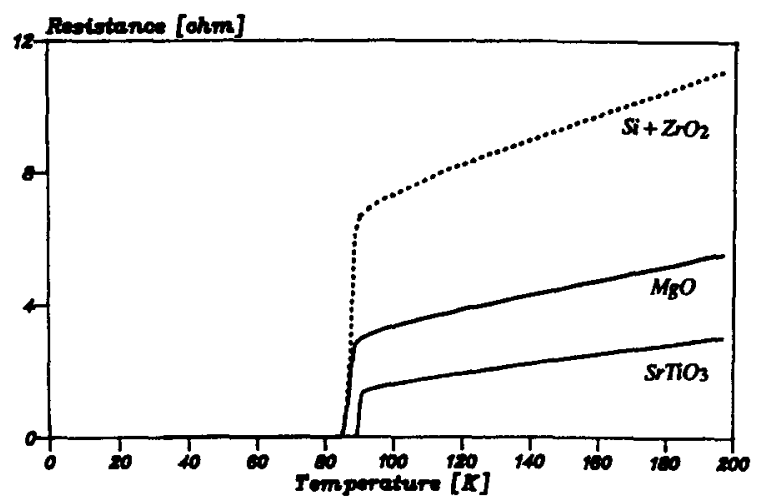

FIGURE 2

Resistance versus temperature for $\mathrm{YBaCuO}$ films on $\mathrm{SrTiO}_{3}, \mathrm{MgO}$ and $\mathrm{Si}+\mathrm{ZrO}_{2}$ The $\mathrm{T}_{\text {zero }}$ values are respectivily $89.5,84.6$ and $83.5 K$.

Fig. 2 shows the resistance versus temperature for the three different substrates with optimal substrate temperatures. All resistance measurements show a linear behaviour in the temperature range from $300 \mathrm{~K}$ to $150 \mathrm{~K}$, given by $\mathrm{R}=\mathrm{R}_{0}+\alpha \mathrm{T}$. In fig. 3 the ratio of the residual resistance $R_{0}$ and the resistance $R_{300}$ at $300 \mathrm{~K}$ versus ( $T_{\text {onset }}-\mathrm{T}_{\text {zero }}$ ) is given. We have found an almost linear behaviour, independent of the substrate material.

Critical current measurements have been carried out on the YBaCuO film on $\mathrm{SrTiO}_{3}$ with a $25 \mu \mathrm{m}$ bridge of $100 \mu \mathrm{m}$ length. At $77 \mathrm{~K}$ we found a critical current density of $2 \times 10^{6} \mathrm{~A} / \mathrm{cm}^{2}$. Critical current measurements on the Si films are in progress.

\section{Discussion and conclusions}

Laser ablation is a promising technique for in-situ preparation of high-quality high $\mathrm{Tc}$ films on various substrates. Besides our results on (100) $\mathrm{SrTiO}_{3}$ and (100) $\mathrm{MgO}$, we also have favourable results on Si with $120 \mathrm{~nm}$ buffer layer of $\mathrm{ZrO}_{2}$ with this method.

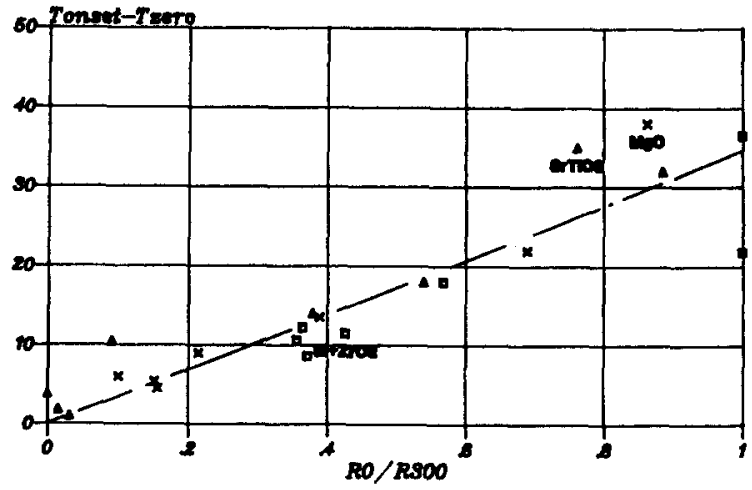

FIGURE 3

The relation between the superconducting transition width $T_{\text {onset }}-T_{\text {zero }}$ and the resistance ratio $R_{0} / R 300$.

The substrate temperature is an important parameter to obtain good properties. Especially, in the case of the Si with $\mathrm{ZrO}_{2}$ buffer layer a strong dependency is found, with an optimum substrate temperature of $725^{\circ} \mathrm{C}$. For $\mathrm{MgO}$ this optimum is about $740{ }^{\circ} \mathrm{C}$ whereas for $\mathrm{SrTiO}_{3}$ the condition is less critical and high $\mathrm{T}_{\text {zero values can be found }}$ in a wide range above $720^{\circ} \mathrm{C}$.

It is known from literature ${ }^{3}$ that the resistivity of high-quality $\mathrm{YBa}_{2} \mathrm{Cu}_{3} \mathrm{O}_{7-\delta}$ films behaves directly proportional to the temperature with almost zero residual value when conduction takes place in the ab-plane. As our films are strongly c-axis oriented we may expect this $R$ vs $T$ behaviour and for this reason we believe that the ratio $\mathbf{R}_{0} / \mathbf{R}_{300}$ is a proper measure for the film quality. Although the first results on Si are very promising, a further study about the influence of the pulse frequency is necessary to derive the best attainable film quality.

\section{References}

1. J. Gao, B. Hauser, W.A.M. Aarnink and H. Rogalla, submitted to Appl. Phys. Lett.

2. D.H.A. Blank, H. Kruidhof and J. Flokstra, J. Phys. D 21 (1988) 226.

3. A. Kapitulnik, Physica C153-155 (1988) 520. 